\title{
Challenges of using Hospital Information Systems by nurses: comparing academic and non-academic hospitals
}

Leila Ahmadian ${ }^{1}$, Nafise Dorosti ${ }^{2}$, Reza Khajouei ${ }^{3}$, Sadrieh Hajesmaeel Gohari ${ }^{4}$

\begin{abstract}
${ }^{1}$ Ph.D. in Medical Informatics, Associate Professor of Medical Informatics, Medical Informatics Research Center, Institute for Futures Studies in Health, Kerman University of Medical Sciences, Kerman, Iran

${ }^{2}$ B.Sc. in Health Information Technology, School of Management and Health Information Sciences, Kerman University of Medical Sciences, Kerman, Iran

${ }^{3} \mathrm{Ph} . \mathrm{D}$. in Medical Informatics, Associate Professor of Medical Informatics, Health Services Management Research Center, Institute for Futures Studies in Health, Kerman University of Medical Sciences, Kerman, Iran

${ }^{4}$ M.Sc. in Health Information Technology, Social Determinants of Health Research Center, Institute for Futures Studies in Health, Kerman University of Medical Sciences, Kerman, Iran
\end{abstract}

\section{Type of article: Original}

\begin{abstract}
Background and aim: Hospital Information Systems (HIS) are used for easy access to information, improvement of documentation and reducing errors. Nonetheless, using these systems is faced with some barriers and obstacles. This study identifies the challenges and the obstacles of using these systems in the academic and non-academic hospitals in Kerman.

Methods: This is a cross-sectional study which was carried out in 2015. The statistical population in this study consisted of the nurses who had been working in the academic and non-academic hospitals in Kerman. A questionnaire consisting of two sections was used. The first section consisted of the demographic information of the participants and the second section comprised 34 questions about the challenges of HIS use. Data were analyzed by the descriptive and statistical analysis (t-test, and ANOVA) using SPSS 19 software.

Results: The most common and important challenges in the academic hospitals were about human environment factors, particularly "negative attitude of society toward using HIS". In the non-academic hospitals, the most common and important challenges were related to human factors, and among them, "no incentive to use system" was the main factor. The results of the t-test method revealed that there was a significant relationship between gender and the mean score of challenges related to the organizational environment category in the academic hospitals and between familiarity with HIS and mean score of human environment factors $(p<0.05)$. The results of the ANOVA test also revealed that the educational degree and work experience in the healthcare environment (years) in the academic hospitals have a significant relationship with the mean score related to the hardware challenges, as well, experience with HIS has a significant relationship, with the mean score related to the human challenges $(\mathrm{p}<0.05)$.

Conclusion: The most important challenges in using the information systems are the factors related to the human environment and the human factors. The results of this study can bring a good perspective to the policy makers and the managers regarding obstacles of using HISs from the nurses' perspective, so that they can solve their problems and can successfully implement these systems.

Keywords: Hospital Information System, Nurses, Barriers, Implementation
\end{abstract}

\section{Corresponding author:}

Sadrieh Hajesmaeel Gohari, Social Determinants of Health Research Center, Institute for Futures Studies in Health, Kerman University of Medical Sciences, Kerman, Iran.

Tel: +98.9134411339, Email: sadriehhajesmaili@yahoo.com

Received: April 25, 2016, Accepted: February 10, 2017, Published: June 2017

iThenticate screening: September 14, 2016, English editing: April 12, 2017, Quality control: June 10, 2017

(C) 2017 The Authors. This is an open access article under the terms of the Creative Commons Attribution-NonCommercialNoDerivs License, which permits use and distribution in any medium, provided the original work is properly cited, the use is non-commercial and no modifications or adaptations are made. 


\section{Introduction}

Nowadays, information and communication technology has affected all areas of human knowledge. The health and treatment sector also has benefitted from this technology due to the large volume of produced information as well as the informational diversity. Accordingly, the Hospital Information System (HIS) has been developed (1). In general, the aim of the HIS is to use computers and communicational instruments to gather, save, process, and extract patient data and to create a link between caring and management information of patients (2). The HIS is designed to manage all aspect of care including its financial, administrative, and clinical (3). The benefits of these systems include easy access to information, improving the quality of documentation, reducing the errors especially the medical errors, improving the quality of patient care, enhancing the information integration, reducing hospitals costs, extending the database, and improving hospital management (4). The need for these systems is caused by factors including the complexity of the hospital as an organization, resources limitation, production of increasing information, the necessity of examining the cost effectiveness, the necessity of increasing the information quality, medical studies and related science (5). Despite the benefits of an HIS, these systems have not been used widely and also, users are unable to use them easily (6). In the recent decades, the role of the nurse as an HIS user has been changed from a passive to an independent and determinant form (7). Enhancing the nurses' responsibilities is implied to have high knowledge and skills and also to be able to make decisions. The role of nurses in patient care is too extensive. Working conditions such as long night shifts and unpredictable working issues, and emergencies increase the likelihood of fatigue and physical inactivity and subsequently raise the risk of working errors. Management of medical prescriptions is the main function of nurses and an important part of the treatment process and patient care. Hence, any medication errors can cause serious problems in the health care system and is considered as a threat for patient safety (9). One of the most common solutions to reduce nursing errors is the Nursing Information System as a sub-system of HIS which can support caring processing in terms of the administrative and clinical aspects, by its specific performance. These systems manage the clinical data, and its purpose is to help nurses in improving the care of the patients via supporting the nursing care process (10). At the moment, there are different computerized systems to register information related to nursing. The function of these systems is more related to the management of the ward's beds, moving and transferring the patients, para clinical results order entry, medication orders entry, registering the number of the physician's visits, and in some systems, documenting the vital signs, registering the nurse's reports, nursing Kardex, nursing shifts and the clinical ward management. Nevertheless, nurses do not use HIS sufficiently to document the provided services to the patients. The studies showed that factors like security issues, technical skills (11), changing the working processes (12) and lack of training and knowledge of users on how to use these systems (2) are the factors which prevent using the information systems in the healthcare sector. These barriers have not been studied from the perspective of nurses as one of the most important employees in the health care sector; therefore, this study examines the challenges and barriers to use the information systems in both academic and non-academic hospitals of Kerman. Identifying these factors can provide a suitable context to develop and use the mentioned systems in hospitals. Also, implementing these systems can provide some solutions to increase efficiency in hospitals.

\section{Material and Methods}

This is a cross-sectional study to investigate the challenges of using nursing information systems from the nurses' perspective that has been carried out in 2015. The research population consisted of 1,467 nurses working in the nonacademic hospitals: (Ayatollah Kashani, Seyed-o-shohada, Alzahra, Fatema-ta-zahra, Razieh firouz, Mehregan, and Arjomand) and the academic hospitals (Shafa, Bahonar, Afzali pour and Shahid Beheshti) of Kerman. The sampling was done using random stratified sampling method. In order to estimate the sample size, formula for calculating the minimum sample size for estimating the proportion was used. According to this formula, 380 nurses were selected as sample size. A questionnaire was used to collect data. For this purpose, the researchers distributed the predesigned questionnaires among the nurses in different wards of the hospital in three working shifts. Before filling the questionnaires, the objectives and importance of study were explained and the security and confidentiality of the information were assured. The data collection tool was the researcher made questionnaire which was designed based on previous similar studies $(2,13)$. For validity of this tool, the experts' opinions including three faculty members in medical informatics field and six nursing supervisors were used. Also, to examine the validity of the questionnaire, Cronbach's alpha was used, and its value was about 0.94 . This questionnaire has two parts. The first part included the demographic information of the nurses such as age, gender, educational degree, job title, work experience in the healthcare environment, and experience with HIS. The second part included 34 questions about the challenges of using HIS in five dimensions including system characteristics, human factors, human environment, organizational environment and the hardware factors. The participants answered the questions based on the 5-point Likert scale from very high to never. Each answer was scored from 1 (very high) to 5 (never). The data analysis was done by 
SPSS version 19 software. In order to analyze the collected data, descriptive statistic, t-test and ANOVA test were used.

\section{Results}

Of the population, 380 were selected as sample size. The questionnaires were distributed between the samples and finally, due to the lack of participation of some nurses in the study, 272 questionnaires were filled. Out of 272 participants, 210 nurses (77\%) were working in academic hospitals and 62 nurses $(23 \%)$ were working in the nonacademic hospitals. In total, 192 participants $(91.5 \%)$ were women and 18 nurses $(8.5 \%)$ were men in academic hospitals. Of nurses working in non-academic hospitals 48 (77.5\%) were women and $14(22.5 \%)$ were men. Age of the participants in both hospitals was 20 to 60 years old. In academic hospitals $178(85 \%)$ and in non-academic hospitals 51 nurses $(82 \%)$ had bachelor's degree and others had associate and master's degree (Table 1).

Table 1. Demographic information of participating nurses

\begin{tabular}{|c|c|c|c|}
\hline \multicolumn{2}{|l|}{ Characteristics } & $\begin{array}{l}\text { Academic hospitals; } \mathrm{n} \\
(\%)\end{array}$ & $\begin{array}{l}\text { Non academic hospitals; } n \\
(\%)\end{array}$ \\
\hline \multirow{2}{*}{ Gender } & Male & $18(8.5)$ & $14(22.5)$ \\
\hline & Female & $192(91.5)$ & $48(77.5)$ \\
\hline \multirow[t]{4}{*}{ Age (year) } & $20-29$ & $62(29.5)$ & $32(51.5)$ \\
\hline & $30-39$ & $69(33)$ & $23(37)$ \\
\hline & $40-49$ & $66(32)$ & $6(10)$ \\
\hline & $50-60$ & $12(5.5)$ & $1(1.5)$ \\
\hline \multirow[t]{3}{*}{ Educational degree } & Associate & $24(11)$ & $10(16)$ \\
\hline & Bachelor & $178(85)$ & $51(82)$ \\
\hline & Master & $8(4)$ & $1(2)$ \\
\hline \multirow[t]{5}{*}{ Job title } & Nurse's aide & $27(13)$ & $10(16)$ \\
\hline & Nurse & $158(75)$ & $43(69.5)$ \\
\hline & Head nurse & $21(10)$ & $8(13)$ \\
\hline & Supervisor & $2(1)$ & $1(1.5)$ \\
\hline & Matron & $2(1)$ & $0(0)$ \\
\hline \multirow{6}{*}{$\begin{array}{l}\text { Work experience in the healthcare } \\
\text { environment (year) }\end{array}$} & Under 1 & $11(5)$ & $7(11)$ \\
\hline & $1-2$ & $22(10.5)$ & $8(13)$ \\
\hline & $2-4$ & $40(19)$ & $19(30.5)$ \\
\hline & $5-10$ & $54(25.5)$ & $21(34)$ \\
\hline & $11-15$ & $16(7.5)$ & $5(8)$ \\
\hline & Over 15 & $67(32.5)$ & $2(3.5)$ \\
\hline \multirow[t]{4}{*}{ Experience with HIS (year) } & Under 1 & $17(8)$ & $11(17.5)$ \\
\hline & $1-2$ & $41(19.5)$ & $12(19.5)$ \\
\hline & $2-4$ & $73(35)$ & $26(42)$ \\
\hline & Over 5 & $79(37.5)$ & $13(21)$ \\
\hline
\end{tabular}

Out of the studied challenges, the challenges related to human environment with total mean score of 3.34 had the highest score. The results of data analysis by separating hospital type (academic and non-academic) showed that the challenges related to human environment had the highest mean (3.33) in the academic hospitals. The challenges related to human factors in non-academic hospitals had the highest mean score (3.5). In the category of human environment, the highest mean score (3.4) was related to "negative attitude of society toward using HIS" and in the category of human factors, "lack of incentive to use system" had the highest mean score (3.63). In total, hardware factors had the lowest mean score $(3.05,2.66$ and 2.75) in both types of hospitals. Generally, the lowest mean score was related to "technical problems of system" (2.35) in both types of hospitals (Table 2). The results of t-test showed significant relationship between the gender of the participants and the mean score of challenges of organizational environment in the academic hospitals $(p<0.05)$. So that, men were more agreed that the organizational environment barriers play an important role in the implementation of HIS. In addition, there was a significant relationship between being familiar with the HIS and the mean score assigned to human environment factors in the academic hospitals, .i.e. those who were not familiar to HIS, acknowledged human factors less than other factors as a barrier to use HIS. The results of ANOVA in both groups revealed that there is no significant relationship between demographic information of the participants (age, job, educational degree, work experience in 
the healthcare environment and experience with HIS) and the mean scores of challenges in hospitals. But, there was a significant relationship between the educational degree and working experience in the healthcare environment and the mean score assigned to hardware challenges in the academic hospitals. So that, the participants with lower educational degree stated hardware challenges as a barrier to use HIS. Also, the participants with higher working experience in the healthcare environment stated hardware challenges as barriers to use HIS. Additionally, there was a significant relationship between experience with HIS and the mean score assigned to human challenges. Therefore, participants with higher experiences with HIS were more interested and motivated to use these systems.

Table 2. Scores related to barriers of using hospital information system in terms of hospital type

\begin{tabular}{|c|c|c|c|}
\hline \multirow[t]{2}{*}{ Dimensions } & \multirow[t]{2}{*}{ Criteria } & \multicolumn{2}{|c|}{ Mean score } \\
\hline & & $\begin{array}{l}\text { Academic } \\
\text { hospital }\end{array}$ & $\begin{array}{l}\text { Non-academic } \\
\text { hospital }\end{array}$ \\
\hline \multirow{12}{*}{$\begin{array}{l}\text { System } \\
\text { characteristics }\end{array}$} & Technical problems of system & 2.35 & 2.35 \\
\hline & Incompatibility of user interface with users needs & 2.72 & 2.82 \\
\hline & System incompatibility with workflows in manual system & 2.84 & 2.79 \\
\hline & Difficulty to work with system & 3.17 & 3.27 \\
\hline & $\begin{array}{l}\text { Non-compliance of system with the previous electronic } \\
\text { systems }\end{array}$ & 3.20 & 2.97 \\
\hline & Low speed of computer & 2.49 & 2.74 \\
\hline & Possibility of legal problems when working with system & 2.98 & 3.02 \\
\hline & Loss of confidentiality of information & 2.85 & 3.35 \\
\hline & Display of unnecessary information in system & 3.01 & 3.56 \\
\hline & Inappropriateness of some default information & 2.94 & 3.29 \\
\hline & Difficulty of access to information & 3 & 3.42 \\
\hline & Security threat of information & 3 & 3.16 \\
\hline \multirow[t]{7}{*}{ Human factors } & Time consuming work with HIS & 3.20 & 3.37 \\
\hline & Lack of interest to work with computer & 3.29 & 3.44 \\
\hline & Lack of sufficient skill for working with computer & 3.15 & 3.53 \\
\hline & Lack of knowledge about the functionality of system & 3.14 & 3.50 \\
\hline & $\begin{array}{l}\text { Resistance to change from manual systems to } \\
\text { computerized systems }\end{array}$ & 3.37 & 3.45 \\
\hline & Uncertainty about the usefulness of system & 3.25 & 3.58 \\
\hline & No incentive to use system & 3.46 & 3.63 \\
\hline \multirow[t]{4}{*}{ Human environment } & Reduced communication with patients & 3.25 & 3.32 \\
\hline & Reduced communication with colleagues & 3.30 & 3.45 \\
\hline & Negative attitude of colleagues toward HIS & 3.38 & 3.27 \\
\hline & Negative attitude of society toward using HIS & 3.40 & 3.61 \\
\hline \multirow{8}{*}{$\begin{array}{l}\text { Organizational } \\
\text { environment }\end{array}$} & Lack of time under clinical work pressure & 2.74 & 2.84 \\
\hline & Inadequate training about HIS & 2.69 & 2.92 \\
\hline & Failure to fix the system completely & 2.80 & 2.82 \\
\hline & Lack of space in workplace & 2.78 & 3.06 \\
\hline & $\begin{array}{l}\text { Lack of user participation in the design of system before } \\
\text { installation }\end{array}$ & 2.87 & 3.06 \\
\hline & Non-compliance with organizational culture & 3.13 & 3.50 \\
\hline & Lack of computer's staff when necessary & 2.51 & 3.16 \\
\hline & Incorrect managerial decision making in hospital & 3.04 & 3.50 \\
\hline \multirow[t]{2}{*}{ Hardware factors } & Network failure & 2.50 & 2.92 \\
\hline & Lack of computers in hospitals & 2.83 & 3.18 \\
\hline
\end{tabular}

\section{Discussion}

The results of this study revealed the challenges and the barriers of using HIS implementation from the perspective of nurses working in academic and non-academic hospitals. In the academic hospitals, the most common and important challenges were related to the human environment factors and in the non-academic hospitals the issues concerning the human factors were the common and important challenges. Among the human environment factors, 
the highest mean score was related to "negative attitude of society toward using HIS" and among the human factors "no incentive to use system" had a higher mean score. The results of this study revealed that the nurses in the academic hospitals stated the negative attitude of society toward using HIS as the largest challenges. While, in the studies conducted by Ahmadian et al. (2), on the challenges of the HIS from the perspective of authorities of information technology department and the hospital managers, hardware factors and "network failure" have been stated as the most important challenges in using these systems. The difference in the results can be due to differences in the field and expertise of participants of these two studies. Because, computer engineers in the information technology department are more involved with the hardware and software problems problems related to network of the HIS and subsequently, they are responsible for solving these issues. However, nurses and other experts in the healthcare sector interact with patients directly, and are the final users of information systems, therefore they are further involved with systems and recording information and the related issues to information (14). The studies highlighted the role of the main users (15) and also society's attitude (16) in convincing nurses to use the HIS. The negative attitude about the systems is more likely due to earliest models of these systems, the lower speed, personnel's unawareness and anxiety about the safety and legal issues. In order to reduce these conflicts, the active participation of the final users in designing and developing HIS and in-service training, can be a suitable solution for this problem. In the non-academic hospitals, the majority of the nurses stated the human factors, and among those "no incentive to use system" was the main challenge to use the information systems. The basic salary of nurses in the non-academic hospitals is lower than academic and governmental hospitals; therefore, financial motivation plays an important role in this regard (17). Some policies such as payment based on performance pattern (Qasedak) implemented in the governmental hospitals, despite some opponents, has urged the nurses to document all the services in the ward to calculate their salary. The hardware factors from the perspective of nurses in two hospitals had lower priority as the challenge in using the HIS. While in the previous studies, the technological factors such as the software and hardware factors were reported as the most important barriers $(2,18)$. This difference in results is more likely because of the differences in study population. Lack of computers in hospitals was introduced as one of the main barrier of hardware factors category. This shortcoming causes some difficulties for nurses to access HIS, and this affects the information entry and time of patients caring. This also leads to decrease nurses' motivation to use these systems. Matching information systems and workload of nurses, and adding the functionalities to facilitate their performance will result in increasing users' satisfaction (19). Given the current policies of hospitals to create electronic files beside paper files caused an increase in the workload of nurses, especially in clinical departments. In-service training and paying a salary based on performance have increased the awareness and motivation of nurses, and finally resulted in promotion of HIS. The major limitation of this study was lack of cooperation of some nurses to fill the questionnaire. This study is the first study which reveals the challenges and barriers of using HIS implementation from a perspective of nurses in two different types of hospitals.

\section{Conclusions}

In summary and according to findings of this study, the most common challenges of using information systems in academic hospitals were related to human environment factors. Also, human factors were the most important challenges in the non-academic hospitals. The results of this study can provide effective suggestions to authorities and managers of hospitals, from the perspective of nurses as the most important users of the systems in the healthcare sector, regarding the barriers and challenges of using HIS to solve the problems and implement HIS successfully. It is recommended to use some policies and programs such as in-service training to solve these barriers, and to increase the motivation of users of HIS. This study examined the challenges of using information systems from the perspective of nurses. In order to increase the use of these systems, it is required to conduct other studies on the influencing factors on increasing motivation and interests of nurses to use these systems.

\section{Acknowledgments:}

We appreciate all the nurses who dedicated their time and expertise for doing this study. In addition, we appreciate the medical informatics research center of the Kerman University of Medical Sciences for supporting us with research grant No.93.11.

\section{Conflict of Interest:}

There is no conflict of interest to be declared.

Authors' contributions:

All authors contributed to this article equally. All authors read and approved the final manuscript. 


\section{References:}

1) Abbasi Moghadam MA, Fayaz Bakhsh A. Hospital information system utilization in Iran: a qualitative study. Acta Med Iran. 2014;52(11):855-9. PMID: 25415820.

2) Ahmadian L, Khajouei R, Nejad SS, Ebrahimzadeh M, Nikkar SE. Prioritizing barriers to successful implementation of hospital information systems. J Med Syst. 2014 Dec;38(12):151. DOI: 10.1007/s10916014-0151-9. PMID: 25367647.

3) Vafaee A, Vahedian M, Esmaeily H, Kimiafar K. Views of Users towards the Quality of Hospital Information System in Training Hospitals. J Res Health Sci. 2010;10(1):47-53. PMID: 22911917.

4) Salehinajad S, Ahmaidn L, Khajouei R. Effects of Health Information Systems in Iran: a Systematic Review. Journal of health information management. 2014;11(2):270-84.

5) Sadoughi F, Kimiafar K, Ahmadi M, Shakeri MT. Determining of factors influencing the success and failure of hospital information system and their evaluation methods: a systematic review. Iran Red Crescent Med J. 2013 Dec;15(12):e11716. DOI: 10.5812/ircmj.11716. PMID: 24693386. PMCID: PMC3955501.

6) Or C, Dohan M, Tan J. Understanding critical barriers to implementing a clinical information system in a nursing home through the lens of a socio-technical perspective. J Med Syst. 2014 Sep;38(9):99. DOI: 10.1007/s10916-014-0099-9. PMID: 25047519.

7) Kahouei M, Baba Mohammadi H, Askari Majdabadi H, Solhi M, Parsania Z, Said Roghani P, et al. Nurses' perceptions of usefulness of nursing information system: module of electronic medical record for patient care in two university hospitals of iran. Mater Sociomed. 2014 Feb;26(1):30-4. DOI: 10.5455/msm.2014.26.30-34. PMID: 24757398. PMCID: PMC3990381.

8) Caruso CC. Negative impacts of shiftwork and long work hours. Rehabil Nurs. 2014 Jan-Feb;39(1):16-25. DOI: 10.1002/rnj.107. PMID: 23780784. PMCID: PMC4629843.

9) Alsulami Z, Conroy S, Choonara I. Medication errors in the Middle East countries: a systematic review of the literature. Eur J Clin Pharmacol. 2013 Apr;69(4):995-1008. PMID: 23090705. DOI: 10.1007/s00228012-1435-y. PMCID: PMC3621991.

10) Abdrbo AA, Zauszniewski JA, Hudak CA, Anthony MK. Development and testing of a survey instrument to measure benefits of a nursing information system. Perspect Health Inf Manag. 2011;8:1c. PMID: 21796265. PMCID: PMC3142137.

11) Tieu L, Sarkar U, Schillinger D, Ralston JD, Ratanawongsa N, Pasick R, et al. Barriers and Facilitators to Online Portal Use Among Patients and Caregivers in a Safety Net Health Care System: A Qualitative Study. J Med Internet Res. 2015;17(12):e275. DOI: 10.2196/jmir.4847. PMID: 26681155. PMCID: PMC4704882.

12) Kruse CS, Goetz K. Summary and frequency of barriers to adoption of CPOE in the U.S. J Med Syst. 2015 Feb;39(2):15. DOI: 10.1007/s10916-015-0198-2. PMID: 25638719. PMCID: PMC4312581.

13) Gravel K, Legare F, Graham ID. Barriers and facilitators to implementing shared decision-making in clinical practice: a systematic review of health professionals' perceptions. Implement Sci. 2006;1:16. DOI: 10.1186/1748-5908-1-16. PMID: 16899124. PMCID: PMC1586024.

14) Eikey EV, Murphy AR, Reddy MC, Xu H. Designing for privacy management in hospitals: Understanding the gap between user activities and IT staff's understandings. Int J Med Inform. 2015 Dec;84(12):1065-75. DOI: 10.1016/j.ijmedinf.2015.09.006. PMID: 26467571.

15) Yuan CT, Bradley EH, Nembhard IM. A mixed methods study of how clinician 'super users' influence others during the implementation of electronic health records. BMC Med Inform Decis Mak. 2015;15:26. DOI: 10.1186/s12911-015-0154-6. PMID: 25889076. PMCID: PMC4407776.

16) Feldman SS, Schooley BL, Bhavsar GP. Health information exchange implementation: lessons learned and critical success factors from a case study. JMIR Med Inform. 2014;2(2):e19. DOI: 10.2196/medinform.3455. PMID: 25599991. PMCID: PMC4288070.

17) Clarke A, Adamson J, Sheard L, Cairns P, Watt I, Wright J. Implementing electronic patient record systems (EPRs) into England's acute, mental health and community care trusts: a mixed methods study. BMC Med Inform Decis Mak. 2015;15:85. DOI: 10.1186/s12911-015-0204-0. PMID: 26466894. PMCID: PMC4607108.

18) McGinn CA, Grenier S, Duplantie J, Shaw N, Sicotte C, Mathieu L, et al. Comparison of user groups' perspectives of barriers and facilitators to implementing electronic health records: a systematic review. BMC Med. 2011;9:46. DOI: 10.1186/1741-7015-9-46. PMID: 21524315. PMCID: PMC3103434.

19) Khajouei R, Wierenga PC, Hasman A, Jaspers MW. Clinicians satisfaction with CPOE ease of use and effect on clinicians' workflow, efficiency and medication safety. Int J Med Inform. 2011 May;80(5):297309. DOI: 10.1016/j.ijmedinf.2011.02.009. PMID: 21419695. 